\title{
Exploring the Determinants Affecting E-Government Cloud Adoption in China
}

\author{
Haiying $\mathrm{Ji}^{1,2}$ \& Yikai Liang ${ }^{2}$ \\ ${ }^{1}$ School of Management Science \& Engineering, Shandong Normal University, Jinan, China \\ ${ }^{2}$ School of Management, Shandong University, Jinan, China \\ Correspondence: Haiying Ji, School of Management Science \& Engineering, Shandong Normal University, \\ Jinan, 250014, China. E-mail: juliaji@163.com
}

Received: December 30, 2015

Accepted: February 14, 2016

Online Published: March 15, 2016

doi:10.5539/ijbm.v11n4p81

URL: http://dx.doi.org/10.5539/ijbm.v11n4p81

\begin{abstract}
Cloud computing is the popular tendency in information application and services, and E-Government cloud is no exception. This study uses a case study to explore the determinants of E-Government cloud adoption in China which is influenced by multiple factors. In this study, a combinational model based on the TOE and DOI is applied to gain insights concerning all contextual influences on the adoption of E-Government cloud in China. The results show that the positive and negative influences from cloud technology characteristics, organizational and environmental context, which can reflect the adoption of E-government cloud. These findings not only contribute to academic research, but also expand the understanding of E-government cloud applications.
\end{abstract}

Keywords: e-government cloud, IS adoption, diffusion of innovation, technology-organization-environment, case study

\section{Introduction}

Cloud computing is a popular technology that indicates the new generation architecture (Alshamaila et al., 2013). While cloud infrastructure and services have been extensively applied by individuals and enterprises for a period of time, governments have begun to consider cloud computing as a design framework for supporting the E-government tasks until just recently. Despite the trends cloud remains for some unfamiliar problems. In China, cloud computing has already formed the significant influence in IT industry, the academic research is still very lacking (Lian, 2015). Therefore in order for a combination between cloud and E-government it is high time to explore the driving forces which may affect attitude of adoption decision by governments. The objective of this paper is thus to investigate what factors and how they influence governments on adopting E-government cloud. Then we adopt an exploratory case study approach. To guide our case analysis, we begin with the traditional, accepted IT/IS adoption models, e.g. diffusion of innovation theory (DOI), technology -organization-environment (TOE) framework, and technology task fit (TTF) include the influences of models and analyze the organizational adoption of E-government cloud in China context. We develop our combination model that illustrates the factors of adoption attitude to E-government cloud.

\section{Literature Review}

\subsection{Cloud Computing and E-Government Cloud}

Cloud computing is organic fusion between IT efficiency and business agility. At present, the research centralize in the topics of technology and implementation of cloud computing, such as cost and risk of cloud, secure storage and auditing rules (Mazhelis \& Tyrväinen, 2012), ownership of IT resources, security (Paquette et al., 2010), privacy risk. Dutil (2008) found that the limited key factor of development of E-government is the service does not reach the designated position, thus the concept of cloud computing was raised, and presented the E-government cloud combines E-government with cloud computing. As the application of cloud, a large number of information resources of E-government can be managed and integrated, improve service efficiency and quality of the electronic government affairs, as a result, the efficiency and quality of E-government service can be improved, and the operational costs can be also reduced. Since then, cloud environment of E-government development has become one of hot topics in the academic and practice. 


\subsection{Adoption Model}

The IT/IS adoption theories and models can be divided into organizations and individuals. The diffusion of innovation (DOI) theory and the Technology-organization-environment (TOE) framework are widely referenced in IT/IS adoption researches at organizational level. On the contrary, some authorized theories, e.g. the technology acceptance model (TAM) (Davis, 1989), and the technology task fit (TTF) (Goodhue \& Thompson, 1995) are not referenced in these researches owing to they are fit for an individual's decision.

Diffusion of innovations (DOI) is one of the critical theory in organization IT/IS adoption (Alam, 2009). The theory explains the factors of innovation diffusion influence organization, relative advantage, compatibility, complexity, observability and trialability. Rogers (2003) proposes, innovation is the communication process with every channel in the social system, individual factors, internal organizational structure and external characteristics of the organization can all affect the adoption.

TOE considers that the adoption of the technology innovation could be affected by technology, organization and environment (Drazin, 1991). Technology means that the external technology including current technology and not yet was adopted technology by enterprises. Organization refers to that descriptive features show the communication in organization, resources and individuals. Environment refers to that cooperators, market factors, competitors, communication with the government and policy environment (Martins \& Oliveira, 2010; Kuan \& Chau, 2001; Oliveira \& Martins, 2011).

TOE and DOI can systematically reveal factors from inside and outside the organization and technology characteristics, but TOE do not specify individual characteristics and DOI do not consider the influence of environment. Therefore, the combination of above models can contribute to providing more overall factors of technology, organization and environment.

\section{Research Methodologies}

\subsection{Case Study Approach}

As previously noted, there is restricted existing knowledge of the adoption for E-government cloud in China. We decided to use an exploratory qualitative case study approach. The cloud computing program is identified as an efficient method to improve IT capacity of governments because it includes some advantages, e.g. the speedy deployment, lower maintenance costs. In China, however, the cloud computing remains an introductory stage. In particular, most governments are not aware of the cloud computing solutions.

The purpose of this study is to identify the determinants of organizations' decisions to adopt E-government cloud in governments where few studies exist. This fact prompted us to use a case study that answers the "how" aspect of the phenomenon (Yin, 2009) identified in our research question. The case study is well suited for this research, because case study is an 'empirical inquiry that investigates a contemporary phenomenon within its real-life context, (Dubé \& Paré, 2003) and the case study is a powerful methodology that allows researchers to explore IT/IS in natural settings, and generate theories from practice (Benbasat et al., 1987).

E-government cloud is a burgeoning type of technology in the governments which have not been widely adopted and utilized yet. Therefore, we should adopt a qualitative research method, and establish a theoretical framework through data collection, analysis and abstract. Thus, case study is an applicable methodology for this study.

\subsection{Data Collection and Analysis}

We collect related data from E-government cloud case, set out interviews outline under the guidance of the theory of literature. The multiple investigators can promote confidence and reliability of the results. Multiple data collection methods (interviews and secondary data) can allow for triangulation of sources and add the reliability of the findings (Yin, 2009).

The primary data collection method is interviews with managers and staffs with different roles in the governments. Face-to-face interviews are done by two researchers. Structured and semi-structured questionnaires are posed during the interviews. The sessions are semi-structured to permit the interviewers to probe themes and opportunities that arose during the conversation with interviewees. The interview questions are tailored according to related literatures in IS domain. Interview topic focuses on the determinants and resistances of implement E-government cloud (Iyer \& Banerjee, 2015).

This research adopts the combination of individual depth interview and focus group interviews. Among them, the individual depth interview achieved 12 interviewees, which last approximately 30 minutes to 60 minutes, while the focus group interviews are organized four times (average 3 interviewees in each group), lasting for 60 minutes to 90 minutes for government managers, and IT staff and cloud service providers. With using two kinds 
of interview methods, we cannot only deeply understand the interviewees' attitude towards E-government cloud, but also inspire interviewees each other in an open environment. In the interview, we audio-record the interviews with the consent of the respondents, and collate and transcribe all interviews. Thus, we obtain the first-hand data. Secondary data collection is focus on government plan and documents provided by the governments. The government plans included details on E-government objectives and demands.

Subsequently, we transcribed, analyzed and used qualitative analysis software to code the interview data. The data from each case were initially analyzed separately. The within-case analysis encouraged the development of insights about each interview record. The a priori concepts identified were used to guide coding for each case, i.e., to search for the key factors, with the possibility for innovative concepts to emerge from the analyses. After analyzing both records, a comprehensive analysis was carried out to identify similarities and differences in the adoption factors in multiple dimensions. Comparing studies allowed us to discover insights beyond initial impressions of the data. This analysis offered the opportunity to capture novel findings and identify significant differences between the interviews along each concept that might influence the organizational adoption. As a result, we were in a position to derive a theoretical model to describe the adoption of E-government cloud in all interviews.

\section{Findings}

Similarities and differences between cases were identified. While all cloud projects had different significantly intentions to adopt the E-government cloud (Hidayanto et al., 2015). The dissimilar intentions might be due to the differences in E-government cloud adoption driven factors .Emergent concepts will be discussed as they appeared from the case analyses. The findings are organized as follow: technology characteristics, organizational context, and environmental context (Lin \& Chen, 2012).

\subsection{Technology Characteristics}

1) Compatibility

Rogers defines compatibility as 'the degree of the innovation fits with the existing values, practices and requirements of adopter.' Compatibility is a key factor of innovation adoption (Azadegan \& Teich, 2010). When the innovation has more compatibility with the existing values, experiences and requirements of adopters, indeterminacy will reduce (Lin \& Chen, 2012). Therefore, the rate of adoption will add. Obviously, compatibility was the key focus which the interviewees had mentioned about adopting E-government cloud in governments. The analysis can be broadly classified into technology fit and organization fit. Technology fit refers to services of E-government cloud to government staffs can support the work without significant changes of previous system and data structure; while organization fit refers to E-government cloud environment can meet the organizations' plan and information target.

In technology fit dimension, some interviewees were not familiar with E-government cloud thought cloud is incompatible with their current work, and they need to study new knowledge of cloud. The compatibility between cloud computing with the original e-government system is another important factor in the expediting of a tendency of government cloud. Because the governments can't abolish the existing government system with the use of cloud computing technology, instead migrating the original system to the cloud platform. Therefore, the low level of transferability, operation, maintenance, security, stability and compatibility of existing system, which also increased concerns of adopting cloud computing of government.

I believed that the cloud service can reduce time to sustain our daily work. The service providers also can help our departments reduce some cost and efforts because we don't need to consider how to implement and maintain the IS. We did not consider the technology implement of cloud.

In organization fit dimension, some interviewees thought the cloud is the best way to achieve the governments' need (reduce cost, green information, information security et al.). The matching degree between cloud computing technical and organizational strategy is one of the decisive factors of promoting the adoption by the governments (Oredo \& Njihia, 2014). Governmental organizations scattered resources, information technology model is fragmented, so the application of cloud computing technology to build e-government public cloud platform is an effective way to promote government business collaboration and information sharing (Ho \& Im, 2013).

Government departments have a tendency to strengthen the evolution and use of E-government affairs information resources, and improve the security capability of government information system. They would like to make a significant breakthrough in information sharing and business collaboration through E-government cloud. By introducing the construction mode of cloud platform, the organizations can take full advantage of the cloud technology to organize IT for examination and approval of optimization, change the function of the IT 
department and staff, improve the efficiency of resource utilization, reduce operational costs and improve service satisfaction of public platform so as to optimize the sector structure, control the investment spending, and improve social reputation, which can make the department to prefer to t adopt the E-government.

2) Relative advantage

Relative advantage is an important driving of whether the benefits of an innovation to adopters exceed the previous state (Hashemi et al., 2013; Lin \& Chen, 2012). Before adopters make the decision of adopting an innovation, they always want to know what relative advantages are relevant to them (Rogers, 2003). The relative advantages with adopting E-government cloud which interviewees mentioned should be appeared to personal and organizational (Dedrick \&West, 2004).

At the personal level, some interviewees in IT department of government thought they can get out of IT operational work and analyze the data, which can reduce the workload and promote their own ability. The other key advantage of the cloud is the convenience which refers to that the use of cloud is not limited by time.

People in information center have numerous levels with changes in both concept and function. For them, cloud is to promote their development in the future, because most of their energy in the information center is basically focused on computer room management under the original traditional pattern and other low level of technology. But after applying the cloud platform, they can be free from the management and other basic operations of IT. As a consequence, they will have more time and energy to study their department's business. So it will increase the capacity for them.

At the organizational level, some interviewees thought the advantages of E-government cloud are not obvious (Lin \& Chen, 2012). This may because their organizations are lack of understanding of E-government cloud. However, the benefit of the E-government cloud could be aware when the E-government cloud becomes a successful model and service. Some IT staffs in adopted governments also know that the E-government cloud can provide virtualization service, accelerate the procurement, improve the efficiency of resource utilization and deployment cycle, reduce operational costs, and improve service satisfaction in public. The E-government cloud also can provide a positive influence on the public service to the public.

Nonetheless, after using the cloud platform, the purchasing cycle will be very short. It just needs to submit an application, and we will give them the resources of cloud, which just takes less than a week to get access to the resources and deploy the application. I believe they will be positive to the cloud platform migration after they are aware of the benefits......

Although the interviewees cannot reach an agreement with the relative advantage of the cloud to government and E-government, the possible reason as follows: Firstly, the E-government cloud may have hidden possible costs, including recruitment IT staff, software and hardware upgrade cost, maintenance cost. Secondly, compared with original architecture, software and data that they may lose control which may lead to concerns about data security when using the cloud. Thirdly, some thought technology performance (stability and reliability of cloud) the interviewees perceived would not reach the government requirements because they thought the cloud was immaturity technology.

\section{3) Complexity}

Complexity is the degree to which E-government cloud is hard to utilize, recognize and realize (Lin \& Chen, 2012). According to Rogers (2003) the complexity of E-government cloud is passive to the rate of organizational adoption. A lot of interviewees considered that a cloud solutions would be more complicated than the current IT and IS especially from the chaos advertisement of IT experts and cloud providers (Ifinedo, 2011). However they believed that if the cloud providers and operations can't provide services of cloud operations, extra studying knowledge about the E-government cloud may be a problem for them, and some thought that E-government cloud can be difficult to learn because they were short in the cloud techniques and IT knowledge.

Before many departments do not understand the cloud model, they may feel that the cloud platform will bring a greater work than the previous workload after application of cloud platform, and the difficulty of reconciling the overall relatively.

E-government cloud hardware and software-based unified support have maintained by the service providers, and the cloud center to city departments, according to the amount of the charge, which paid to provide cloud server, cloud disaster recovery, exclusive service, operation and maintenance services, cloud hosting service and other services. It is easy to use. 


\section{4) Observability}

Observability is relative to the visibility of successful cases and practices (Rogers, 2003). When the E-government cloud is observable to other technology, it will add the rate of organizational adoption (Lin \& Chen, 2012). Most interviewees showed that their organization would not accept an emerging technology unless the superior organizations and leaders can provide a specific program and the technology can include a lot of benefits in comparison with current technologies. Some interviewees pointed out that 'cloud computing' is still a concept, therefore its advantages and effectiveness are still not clear. Besides this, because most subordinate organization (city level) is unlikely to take risks to build the E-government cloud if some policies made by superior organization (province level) are not given. Thus successful E-government cases and models to demonstrate the worth of the cloud adoption is an important thing when cloud providers promote the concepts and technologies.

Currently there are not sufficient commercial applications based on cloud computing. We don't know what benefits we will obtain when we use the E-government cloud.

5) Trialability

Trialability refers to that the adopting organizations can experiment with the E-government cloud services on a limited basis (Rogers, 2003). Based on DOI, trialability of the E-government cloud will add the rate of organizational adoption (Lin \& Chen, 2012). All the interviewees would like to try to use E-government cloud in their works and they gradually knew the advantages of using the cloud solutions. However, E-government cloud is not widespread adopted in all organizations. Some organizations start to plan E-government cloud but not implementation, which because they were not sure if the E-government cloud will benefit their work and organizations.

Now, the effect of cloud has no data to support and the effect of the cloud need to observe.

\subsection{Organizational Context}

The organization context is defined in terms of the resources available to support the adoption of an innovation (Lippert \& Govindarajulu, 2006), it refers to the characteristics of the government that facilitate or constrain the adoption and implementation of the E-government cloud (Cellary \& Strykowski, 2009). Multiple factors influence the relationship between organizational characteristics and the adoption of E-government cloud, including top management support, organization inertia, the scale and complexity of information resource( government department size), IT knowledge of cloud (Low et al., 2011; Xu \& Quaddus, 2012), which is the internal situation of adopting and implementing the strategy of cloud. It reflects the conditions within the organization whether there are sufficient resources and supports to adopt cloud. It is important factors to adopt cloud and IS migration to cloud.

\section{1) Top Management Support}

Top management support in the organization is very supportive of E-government cloud because it guides the allocation of resources, the integration of services, and the re-engineering of processes (Oliveira et al., 2014). In fact, the E-government cloud solution was initiated by the top management. Top management that recognizes the advantages of E-government cloud will likely allocate the necessary resources for its adoption and influence the organization's members to implement the change (Dutta et al., 2013). In the interview, we got that top managers although were lack of understanding of the cloud computing, usually made decision of adoption of cloud with the pressure of superiors. As a result, they indirectly made the decision of the cloud adoption. Therefore, understanding of the cloud platform, resources controls, innovation, risk perceived influence the formation of the adoption decision. Advantages of cloud computing technology is very obvious, but cloud computing technology may lead to information security problems and may make the top of organizations lose control over resources. If the top of the organization is highly sensitive to information security issues, so this government is likely to slow the process of adoption of cloud computing. In addition, if an organization level control of resources is very sensitive, and the resources of his own department transfer to the other departments under a unified management may weaken the control of resources department leadership ability, and even undermine the power of sector management leadership, then such governments may resist cloud computing technology (Oredo \& Njihia, 2014).

Senior managers usually don't learn how to manage machines and install equipment. In fact they also do not understand specific techniques, but they have a safe production responsibility on the computer room management that is mainly a liability problem. Hence they are very happy because they don't manage the machine room after using the cloud platform without any security responsibility. Otherwise they would have to worry about the computer power supply and fire protection, etc. 


\section{2) Organization Inertia}

Organization inertia is the characteristics that will not change with the environment and technology. The organization inertia have formed by the idea of practices. Procedures will hinder the adoption behavior of new technology (Liao et al., 2008). The original structure, concentration of power and the way of working will have an effect on organization inertia. The greater the organization inertia, the greater they resist emerging technologies. The probability of cloud adoption behavior will be greatly reduced, if some officials fear to increase the difficulty of work.

If you wish to pursue the construction of the cloud, it will break down departmental original circle or ecological, which will break the existing pattern of interests within the department. So it is difficult to adopt the e-government cloud.

\section{3) The Scale and Complexity of Information Resources}

The scale and complexity of information resources refer to the number of staff in the information department, the number and scale of information systems and the complexity of IS migration to cloud. The adoption behavior of the E-government cloud must be influenced by the size and complexity of information resources. The arrangement of information personnel and the transformation of the function are the problems that the organization is required to solve (Oredo \& Njihia, 2014). Moreover, the number of the original systems and the degree of difficulty for IS migration determine whether to adopt cloud or not. Some interviewees propose that organization with less IS operation and fewer requirements of information would adopt the E-government cloud, because they could save the cost instead of employing the special operations teams. Some interviewees propose that the low degree information departments are also willing to move office business system into a cloud platform in the absence of special financial funds.

Some department leaders would get rid of the burden with the E-government cloud, such as small business, information technology demand is not particularly strong, which need to invest a special operations team. Then they will want to use cloud to move out of its own information services.

\subsection{Environmental Context}

The environment context is the external factors affecting organizations to adopt E-government cloud, which reflects the external constraints and feasible conditions, which affect organization in the process of adoption of E-government cloud (Cao et al., 2014). Researchers admitted that external factors on the organization influence the adoption decision, which influenced by the nature of the cloud industry, access to resources supplied by others, and interactions with others. In the interview, we found that government departments face many problems in the process of adoption of E-government cloud, such as the financial support from the finance department, the feasible policies and standards and the recognition of cloud service object. Currently, China's environment is a neutral factor because the government's policy is still brewing, the public hold the wait-and-see attitude, and the number successful application cases of cloud computing in government are small, the effect is not obvious.

\section{1) Financial Commitment Support}

The special financial fund is a resource of information construction and maintenance for E-government. One of the major hinders for E-government cloud in the government organizations is the cost (e.g. purchasing service costs, use training costs, recruitment, management costs, et al.). Therefore, a government's financial commitment is the importance to the success of the E-government cloud solution. In the pilot project, the cost was incurred by superior government financial budget, which contributed to the successful implementation of the E-government cloud pilot project. Interviewees mentioned that the capital source of the government information technology investment is primarily financial commitment. Therefore the relevant policies made by the government will promote the development of investment planning for cloud projects as soon as possible.

Business application systems of some departments are so complex, and comprise more functions, which cost tens of millions of financial appropriation.

2) Policies and Standards

As cloud computing technology is a new information technology, so various government departments and the public hold wait-and-see attitude for the adoption and application of the E-government cloud. Once the relative national policy and the successful cases appear, then cloud computing will certainly be widely applied. The alignment with the current national policy in China is also vital and governments may not design and implement cloud architecture with conflicts with national policy (Zissis \& Lekkas, 2011).

The government policies in regard cloud computing and E-government have highlighted that cloud computing 
has the potential effect to the development of the E-government affairs, put forward the task of design the E-government public platform based cloud computing, and pointed out that the development of E-government should migrate to the cloud computing model for the first time, which point out the direction for the development of E-government in China. The series of policy proves that the government is paying more and more attention on E-government cloud computing, and guiding the cloud computing in China for further development as soon as possible.

\section{3) Successful Cases}

Local governments and foreign government attach great importance to the exemplary success cases, so the successful cases of cloud computing technology significantly affect the adoption of the Government's decision to E-government cloud. With the development of the cloud technology and related policy planning and standards, all levels of E-government cloud develop rapidly. Some successful cases come out, such as cloud computing and fusion has been carried out positive in Beijing, Shandong and other provinces and cities. The application effect of E-government cloud appears gradually. Some successful cases objectively verified the feasibility and effect of E-government affairs cloud. For groups intending to adopt cloud computing, the successful cases can increase cloud adoption behavior.

There is not any reference model that will be searched. In foreign countries, they take Amazon, Cisco as a reference, and refer to the Amazon more than others. We don't know what and how to do.

\section{Discussion}

Based on the results of IT/IS adoption (Rogers, 2003), this study regards as that organization is more complex than individual, the organization adoption behavior mainly has reflected by the factors of technology characteristics of cloud, organization, and environmental contexts. Based on the findings of the cases, we present a theoretical model that explains the organizational adoption of E-government cloud (Figure 1). In this combination model based DOI and TOE, we explore the impact of government on the adoption of E-government cloud, explore the factors in organizational context such as top management support, organization inertia, scale and complexity of information resources, the factors in environmental context such as financial commitment support, the policy and standards, success cases with the usage of TOE framework, analyze the technology factors of compatibility, relative advantage, complexity, observability and trialability with DOI theory.

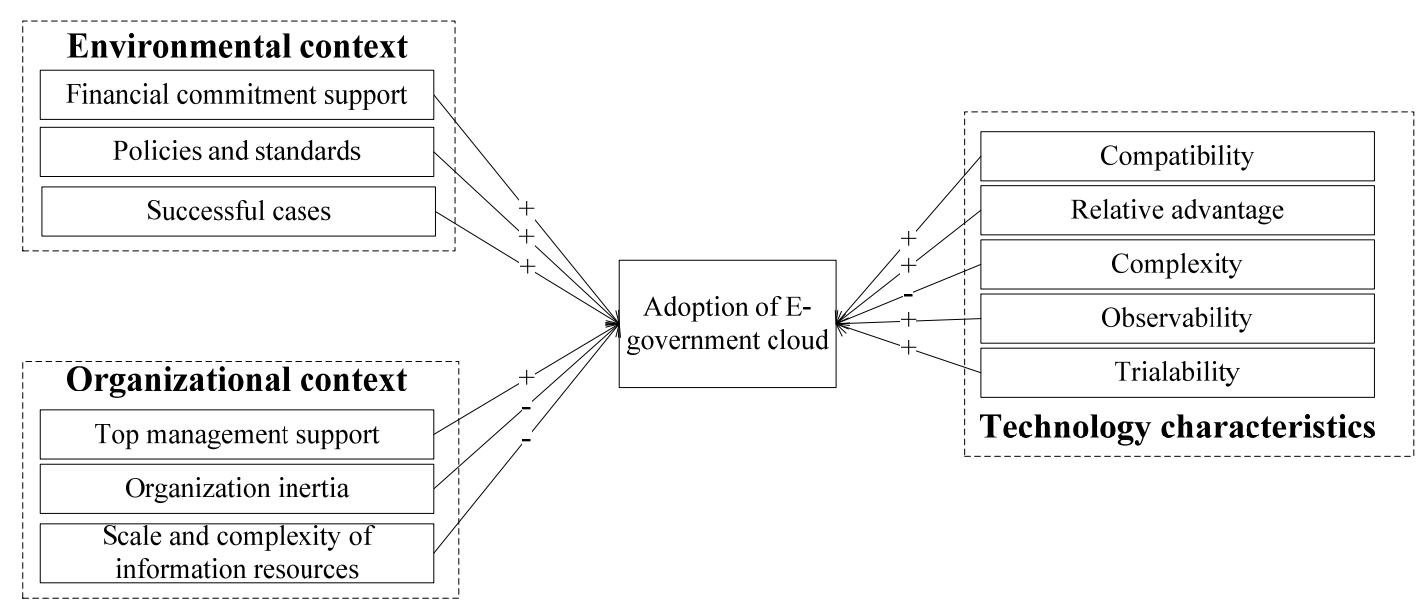

Figure 1. The integration model of E-government cloud adoption

In this model, technology characteristics reflect the technology driving force mechanism. The organizational context reflects the conditions within the organization whether there is sufficient support to adopt cloud. It is crucial factors to adopt cloud and cloud migration. The environmental context is the external factors affecting organizations to adopt E-government cloud, which reflects the external constraints and feasible conditions, which affect the organization of the process of adoption of E-government cloud. The technology characteristics, organizational context and environmental context all have positive and passive influence to adoption of E-government cloud. The more relative advantages, better compatibility, observability and trialability in technology characteristics, the more top management support in organizational context, the more financial commitment support, more detailed policies and standards, more successful cases, the more positive influence of 
adoption. However, the more complexity in technology characteristics and the more organization inertia and bigger scale and complexity of information resources can result in negative influence on the department.

\section{Conclusions}

Cloud computing technology advocating sharing, virtualization and distributed collaboration, lead the trend of modern information technology. Therefore, adoption genesis factors of cloud computing technology have academic significance.

In this research, we conducted the case study of particular instances, the adoption of E-government cloud for Shandong province in China. We interviewed distinct roles in these organizations regarding their opinions and attitude about E-government cloud. Then the data were analyzed with qualitative method. The finds of this study are some categories and concepts derived from the data, as well as a combined model that depict all factors in technology characteristics, organizational context and environmental context in the governments organizations. The study makes important academic contributions to the domain of research on the adoption of IT/IS. The adoption of IT/IS is a hot domain in recent years, some widely accepted theories such as DOI, TAM, TOE and TTF have been put forward. However, there are some limitations of understanding the IT/IS adoption phenomenon with one theoretical perspective, so this study has combined more than one theoretical model such as DOI and TOE to understand the E-government cloud adoption in the more holistic approaches. The model combines the technology characteristics of cloud, organization, and environmental contexts that underlie the positive influence and negative influence of E-government cloud adoption.

At the same time, the application of cloud computing technology in government, which will promote the progress of the entire information industry and independent innovation capacity of cloud computing products. It is believed that the conclusions of this study will also have some reference value in practices. First of all, the government should fully understand the implementation of the cloud model, they should improve awareness of cloud of top support, and reduce the resistance on organizational inertia. Second, the government should provide reliable policy and standards to guide the construction of E-government cloud, and reduce concerns about the cloud service model of the new technology and also provide some successful cases for governments to learn how to implement.

\section{References}

Alam, S. S. (2009). Adoption of internet in Malaysian SMEs. Journal of Small Business and Enterprise Development, 16(2), 240-255. http://dx.doi.org/10.1108/14626000910956038

Alshamaila, Y., Papagiannidis, S., \& Li, F. (2013). Cloud computing adoption by SMEs in the north east of England: A multi-perspective framework. Journal of Enterprise Information Management, 26(3), 250-275. http://dx.doi.org/10.1108/17410391311325225

Azadegan, A., \& Teich, J. (2010). Effective benchmarking of innovation adoptions: A theoretical framework for e-procurement technologies. benchmarking: An international Journal, 17(4), 472-490. http://dx.doi.org/10.1108/14635771011060558

Benbasat, I., Goldstein, D. K., \& Mead, M. (1987). The case research strategy in studies of information systems. MIS Quarterly, 11(3), 369-386. http://dx.doi.org/10.2307/248684

Cao, Q., Jones, D. R., \& Sheng, H. (2014). Contained nomadic information environments: Technology, organization, and environment influences on adoption of hospital RFID patient tracking. Information \& Management, 51(2), 225-239. http://dx.doi.org/10.1016/j.im.2013.11.007

Cellary, W., \& Strykowski, S. (2009). E-Government Based on Cloud Computing and Service-Oriented Architecture. Proceedings of the 3rd International Conference on Theory and Practice of Electronic Governance, 10-13. http://dx.doi.org/10.1145/1693042.1693045

Davis, F. D. (1989). Perceived usefulness, perceived ease of use, and user acceptance of information technology. MIS Quarterly, 13(3), 319-340. http://dx.doi.org/10.2307/249008

Dedrick, J., \& West, J. (2004). An exploratory study into open source platform adoption. Proceedings of the 37th Annual Hawaii International Conference on System Sciences. Retrieved from http://doi.ieeecomputersociety.org/10.1109/HICSS.2004.1265633

Drazin, R. (1991). The processes of technological innovation. Journal of Technology Transfer, 16(1), 45-46. http://dx.doi.org/10.1007/BF02371446

Dubé, L., \& Paré, G. (2003). Rigor in information systems positivist case research: Current practices, trends, and 
recommendations. MIS Quarterly, 27(4), 597-635. http://dx.doi.org/10.2307/30036550

Dutil, P. A., Howard, C., John, L., \& Roy, J. (2008). Rethinking government-public relationships in a digital world. Journal of Information Technology \& Politics, 4(1), 77-90. http://dx.doi.org/10.1300/J516v04n01_06

Dutta, A., Peng, G. C., \& Choudhary, A. (2013). Risks in enterprise cloud computing: The perspective of it experts. Journal of Computer Information Systems, 53(4), 39-48. Retrieved from http://eprints.whiterose.ac.uk/79144/

Goodhue, D. L., \& Thompson, R. L. (1995). Task-technology fit and individual performance. MIS Quarterly, 19(2), 213-236. http://dx.doi.org/10.2307/249689

Hashemi, S., Monfaredi, K., Masdari, M. (2013). Using Cloud Computing for E-government: Challenges and Benefits. International Scholarly and Scientific Research \& Innovation, 7(9), 447-454. Retrieved from http://www.waset.org/publications/17212

Hidayanto, A. N., Abednego, N., Aminah, S., \& Sucahyo, Y. G. (2015). Analysis of Cloud Adoption Determinants by Using BOCR Analysis and DEMATEL. International Journal of Business Information Systems, 18(2). http://dx.doi.org/10.1504/IJBIS.2015.067265

Ho, T. K., \& Im, T. (2013). Challenges in building effective and competitive government in developing countries: An institutional logics perspective. American Review of Public Administration, 45(3), 263-280. http://dx.doi.org/10.1177/0275074013501856

Ifinedo, P. (2011). An empirical analysis of factors influencing internet/e-business technologies adoption by sm SMEs in Canada. International Journal of Information Technology \& Decision Making, 10(4), 731-766. http://dx.doi.org/10.1142/S0219622011004543

Iyer, K. C., \& Banerjee, P. S. (2015). Facilitators and inhibitors in sector wide technology transfer projects in developing economies: An empirical study. Journal of Technology Transfer, 1-26. http://dx.doi.org/10.1007/s10961-015-9456-1

Kuan, K. K. Y., \& Chau, P. Y. K. (2001). A perception-based model for edi adoption in small businesses using a technology-organization-environment framework. Information \& Management, 38(8), 507-521. http://dx.doi.org/10.1016/S0378-7206(01)00073-8

Lian, J. W. (2015). Critical factors for cloud based e-invoice service adoption in Taiwan: An empirical study. International Journal of Information Management, 35(1), 98-109. http://dx.doi.org/10.1016/j.ijinfomgt.2014.10.005

Liao, S. H., Fei, W. C., \& Liu, C. T. (2008). Relationships between knowledge inertia, organizational learning $\begin{array}{llll}\text { and } \quad \text { organization } & \text { innovation. }\end{array}$ http://dx.doi.org/10.1016/j.technovation.2007.11.005

Lin, A., \& Chen, N. C. (2012). Cloud computing as an innovation: Percepetion, attitude, and adoption. International Journal of Information Management, 32(6), 533-540. http://dx.doi.org/10.1016/j.ijinfomgt.2012.04.001

Lippert, S. K., \& Govindarajulu, C. (2006). Technological, organizational, and environmental antecedents to web services adoption. Communications of the IIMA, 6(1), 146-160. Retrieved from http://www.iima.org/CIIMA/17\%20CIIMA\%206-1\%20147-158\%20Lippert.pdf

Low, C., Chen, Y., \& Wu, M. (2011). Understanding the determinants of cloud computing adoption. Industrial Management \& Data Systems, 111(7), 1006-1023. http://dx.doi.org/10.1108/02635571111161262

Martins, M. F., \& Oliveira, T. (2010). Understanding e-business adoption across industries in European countries. Industrial Management \& Data Systems, 110(9), 1337-1354. http://dx.doi.org/10.1108/02635571011087428

Mazhelis, O., \& Tyrväinen, P. (2012). Economic aspects of hybrid cloud infrastructure: User organization perspective. Information Systems Frontiers, 14(4), 845-869. http://dx.doi.org/10.1007/s10796-011-9326-9

Oliveira, T., \& Martins, M. F. (2011). Literature review of information technology adoption models at firm level. Electronic Journal of Information Systems Evaluation, 14(1), 110-121. Retrieved from http://www.ejise.com/issue/download.html?idArticle=705

Oliveira, T., Thomas, M., \& Espadanal, M. (2014). Assessing the determinants of cloud computing adoption: An analysis of the manufacturing and services sectors. Information \& Management, 51(5), 497-510. http://dx.doi.org/10.1016/j.im.2014.03.006 
Oredo, J. O., \& Njihia, J. M. (2014). Mindfulness and quality of innovation in cloud computing adoption. International Journal of Business and Management, 10(1), 144-160. http://dx.doi.org/10.5539/ijbm.v10n1p144

Paquette, S., Jaeger, P. T., \& Wilson, S. C. (2010). Identifying the security risks associated with governmental use of cloud computing. Government Information Quarterly, 27(3), 245-253. http://dx.doi.org/10.1016/j.giq.2010.01.002

Rogers, E. M. (2003). Diffusion of innovations (5th ed.). The Free Press.

Xu, J., \& Quaddus, M. (2012). Examining a model of knowledge management systems adoption and diffusion: A partial least square approach. Knowledge-Based Systems, 27(3), 18-28. http://dx.doi.org/10.1016/j.knosys.2011.10.003

Yin, R. K. (2009). Case Study Research: Design and Methods (Applied Social Research Methods) (4th ed.). Sage Publications, Inc.

Zissis, D., \& Lekkas, D. (2011). Securing e-government and e-voting with an open cloud computing architecture. Government Information Quarterly, 28(2), 239-251. http://dx.doi.org/10.1016/j.giq.2010.05.010

\section{Copyrights}

Copyright for this article is retained by the author(s), with first publication rights granted to the journal.

This is an open-access article distributed under the terms and conditions of the Creative Commons Attribution license (http://creativecommons.org/licenses/by/3.0/). 